* Mestra na área de Direito Internacional e Sustentabilidade pela Universidade Federal de Santa Catarina (UFSC). Pósgraduada em Direito Processual Civil pela Academia Brasileira de Direito Constitucional (ABDConst). Graduada em Direito pela Faculdade Cenecista de Joinville (FCJ). E-mail: amandakburg@hotmail.com

**Doutor em Direito Econômico pela Universidade Federal de Minas Gerais (UFMG/MG); Doctor en Derecho Internacional Económico en la Universidad de Buenos Aires (UBA/ Bs. As.) Argentina; Mestre em Direito, na área de Instituições JurídicoPolíticas, pela Universidade Federal de Santa Catarina (UFSC/SC); Especialista em Comércio Exterior e Integração Econômica no MERCOSUL pela FURG/RS; Graduado em Direito pela Unianchieta de Jundiaí/SP e em Ciências Econômicas pela Universidade Federal do Rio Grande (FURG/RS); Especialista em Administração Universitária pela FURG/RS. Professor Titular credenciado no Programa de Pós-Graduação em Direito da Universidade Federal de Santa Catarina (PPGD/UFSC); Pesquisa Análise Econômica do Direito e Direito Econômico; Coordenador do Centro de Estudos JurídicoEconômicos e de Gestão para o Desenvolvimento (CEJEGD) do Centro de Ciências Jurídicas (CCJ/UFSC). E-mail: evertong@, vetorial.net

***Doutorando do Programa de Pós-Graduação em Direito da UFSC. Mestre em Economia pela UFSC. Bacharel em Administração pela Universidade do Estado de Santa Catarina (UDESC) e Ciências Econômicas pela UFSC. Docente do Departamento de Ciências Econômicas da UDESC. Perito Economista. Vencedor do XVII Prêmio Catarinense de Economia. E-mail: lisandro. nishi@udesc.br

\section{Atualização Monetária Dos Débitos Judiciais Da Fazenda Pública Sob a Perspectiva Do Supremo Tribunal Federal}

\author{
The Monetary Restatement Of The Public Treasury \\ Debts Under The Perspective Of The Brazilian \\ SuPREMe Federal CoURT
}

\section{Amanda Karolini Burg* Everton das Neves Gonçalves** Lisandro Fin Nishi***}

Como citar: BURG, Amanda Karolini; GONÇALVES, Everton das Neves; NISHI, Lisandro Fin. Atualização monetária dos débitos judiciais da fazenda pública sob a perspectiva do supremo tribunal federal. Scientia Iuris, Londrina, v. 25, n. 1, p. 163-177, mar. 2021. DOI: 10.5433/2178-8189.2021v25n1p163. ISSN: $2178-8189$

Resumo: A atualização monetária tem como finalidade a preservação do poder de compra. Entretanto, em se tratando de débitos da Fazenda Pública, no Brasil, a atualização era realizada com uso da taxa de remuneração básica da caderneta de poupança (Taxa Referencial - TR), que por sua natureza se apresenta como taxa de juros. Em termos econômicos e legais, a aplicação da TR era equivocada, pois a atualização monetária deve ser realizada com uso do instrumento adequado para tal finalidade, qual seja, índices de preço. Ocorre que, em setembro de 2017, o Supremo Tribunal Federal manifestou-se a respeito da questão, opinando pela substituição da TR pelo Índice de Preços ao Consumidor Amplo Especial (IPCA-E), em decisão que substituiu uma taxa de juros por um índice de preço nos débitos judiciais da Fazenda Pública. Este artigo tem como objetivo comprovar que a decisão do STF eliminou a falha existente, na medida em que o uso de taxas de juros como instrumento de correção monetária não é economicamente correto. Para tanto, realizou-se uma pesquisa bibliográfica, documental e de caráter explicativo. Concluiu-se que a decisão do STF, de substituir a TR pelo IPCA-E, eliminou o equívoco econômico na atualização dos débitos da Fazenda Pública.

Palavras-chave: Supremo Tribunal Federal. Atualização monetária. Débitos da Fazenda Pública.

Abstract: The purpose of monetary restatement is to preserve purchasing power. However, in the case of Public Treasury 
debts in Brazil, the monetary restatement utilized the basic rate remuneration of saving accounts (Referential Rate - TR), which is, by its nature, presented as an interest rate. In economic and legal terms, the application of the TR was a mistake, because the monetary restatement should be made using the appropriate instrument for that purpose, in this case, price indexes. In September 2017, the Federal Supreme Court (STF) manifested its opinion regarding the replacement of the TR by the Special Extended Consumer Price Index (IPCA-E) in a decision that replaced the Public Treasury judicial debts with a price index. This article aims to prove that the STF decision eliminated the existing flaw, since the use of interest rates as a monetary restatement instrument was not economically correct. For this reason, this study is bibliographic, documentary and explanatory in nature. This paper concludes that the STF decision, which replaced the TR with the IPCA-E, eliminated the economic error in updating the Brazilian Public Treasury debts.

Keywords: Federal Supreme Court. Monetary restatement. Brazilian Public Treasury Debts. 


\section{INTRODUÇÃO}

A questão da atualização (ou correção) monetária, sem sombra de dúvida, está presente no cotidiano dos brasileiros. Todavia, a população em geral detém pouco conhecimento acerca do impacto da indexação monetária na evolução de dívidas. Além disso, o próprio escopo de se corrigir monetariamente valores pode não estar sendo aplicado da forma correta, por desconhecimento, ou até mesmo intencionalmente, com vistas à obtenção de ganhos financeiros em detrimento do equilíbrio econômico-financeiro entre as partes envolvidas.

Outrossim, a utilização de taxas de juros como índice de correção monetária se apresenta problemática, uma vez que, por possuírem metodologias distintas de cálculo, as taxas de juros não guardam relação direta com a variação dos preços. Ou seja, não têm a força de preservar o poder aquisitivo da moeda. Pinho e Vasconcellos (2004) definem taxa de juros em termos do custo de oportunidade de reter moeda. Neste sentido, Nelson e Correia (2015) concordam que os saldos fundiários devem ser atualizados a partir de índices que reflitam a corrosão da moeda em decorrência da inflação, afirmando que a Taxa Referencial (TR) não é um índice com tal desiderato. O referido equívoco, consistente na opção de taxas de juros para fins de atualização monetária, pode gerar prejuízos monetários aos que deveriam estar sendo protegidos contratualmente ou por força de lei.

A questão é complexa, na medida em que o texto de norma cumpre seu papel, ao prever a aplicação de correção monetária, mas sua regulamentação, v.g., caminha em direção diversa, ao instrumentalizar tal correção com taxas de juros, fato que pode anular a intenção do legislador. Nesta direção, a doutrina da Análise Econômica do Direito, também conhecida como Direito e Economia tem papel fundamental. Carvalho e Jobim (2008, p. 240) ensinam:

O Direito e Economia, por outro lado, é uma vertente que se preocupa com as consequências advindas das normas jurídicas no sistema econômico, que reflete, em boa parte, o sistema social como um todo. Essas consequências podem ser boas ou ruins, mas existem, uma vez que o Direito intervém na realidade social. E por gerar consequências reais, muitas vezes as normas jurídicas, sejam leis, sejam decisões judiciais acabam gerando efeitos opostos àqueles originariamente pretendidos por seus emissores.

Outro ponto que merece destaque é o uso intencional de taxas de juros com o objetivo de reduzir o montante financeiro a ser pago em decorrência da correção monetária. Nestes casos, uma parte estaria se beneficiando financeiramente (e indevidamente), apropriando-se de valores que deveriam estar preservando o poder de compra da parte prejudicada.

Salienta-se que a mensuração da inflação é realizada por diversas instituições, como o Instituto Brasileiro de Geografia e Estatística (IBGE), divulgando os índices de preço, como o Índice de Preço ao Consumidor Amplo (IPCA). Logo, nossa legislação e, consequentemente, os operadores do Direito, quando necessário, deveriam valer-se dos índices de preço para efetuar a atualização monetária, o que nem sempre ocorre. 
Nesse sentido, em trabalho de Nishi (2015) concluiu-se que no período de 01/99 a 08/2015, a rentabilidade da TR não conseguiu cumprir a função de correção monetária no Fundo de Garantia por Tempo de Serviço (FGTS). Todavia, o Superior Tribunal de Justiça (STJ), em acórdão publicado em 15 de maio de 2018, no âmbito do Recurso Especial no 1614874, firmou a tese de que "a remuneração das contas vinculadas ao FGTS tem disciplina própria, ditada por lei, que estabelece a TR como forma de atualização monetária, sendo vedado, portanto, ao Poder Judiciário substituir o mencionado índice” (BRASIL, 2018).

A questão é tão importante, que tramita perante o Supremo Tribunal Federal (STF), a Ação Direta de Inconstitucionalidade de n. ${ }^{0}$ 5090/DF (ADI 5090/DF) ${ }^{1}$, cujo pedido consiste na declaração de inconstitucionalidade do art. 13, caput, da Lei n. ${ }^{\circ}$ 8.036/1990 (BRASIL, 1990) e do art. 17, caput, da Lei n. ${ }^{\circ} 8.117 / 1991$, os quais impõem a utilização da TR para fins de correção dos depósitos nas contas vinculadas ao FGTS, por violação à Constituição Federal² (BRASIL, 2019). Ainda, tramita perante a Câmara de Deputado, entre outros, o Projeto de Lei n. ${ }^{\circ}$ 4.566/2008 que versa acerca da correção monetária do FGTS e aguarda manifestação do Senado Federal (BRASIL, 2008).

Ao considerar que casos semelhantes existem não somente no FGTS, mas em contratos privados e outros casos regidos por lei, é imperativo que se comprove a inadequação do uso de taxas de juros como forma de atualização monetária, pretendendo-se contribuir para afastar tais equívocos. Neste diapasão, em setembro de 2017, o STF, ao julgar o Recurso Extraordinário no 870947 (RE 870947), afastou o uso da TR como índice de correção monetária dos débitos judiciais da Fazenda Pública, em favor do IPCA-E (BRASIL, 2017).

Nesse cenário, o objetivo geral deste trabalho é comprovar que a decisão do STF eliminou um equívoco, na medida em que o uso de taxas de juros como instrumento de correção monetária não é economicamente adequado. São objetivos específicos: (i) apresentar o conceito e os tipos de juros; (ii) indicar o conceito de atualização monetária; e (iii) verificar a perspectiva adotada pelo STF acerca da matéria no âmbito do RE 870947. Para tanto, foi realizada uma pesquisa bibliográfica e documental, de caráter explicativo.

\section{DO CONCEITO DE JUROS}

A fim de analisar a decisão citada, proferida pelo STF, é essencial a apresentação de conceitos operacionais, tais como os conceitos de "juros" e de "correção monetária". Assim, as primeiras seções desse trabalho se dedicam ao estudo de tais conceitos.

Para Guerra (2001), os juros são a remuneração do capital (na ótica de quem ofertou capital) ou o custo do capital (na ótica de quem tomou emprestado), também conceituados por Samanez (2010) como "a remuneração do capital empregado", sendo expressos em unidades monetárias (ex.: R\$ 1.000,00).

1 Com previsão de julgamento para 06/05/2020.

2 Em especial, ao art. $5^{\circ}$, inciso XXII, que garante o direito à propriedade, ao art. $7^{\circ}$, inciso III, que dispõe sobre o FGTS e o art. 37, caput, que dispõe sobre a moralidade administrativa (BRASIL, 1988). 
A taxa de juros, por sua vez, é a representação dos juros por unidade de tempo (ex.: $6 \%$ ao ano). Segundo John Maynard Keynes (1996) em sua obra “A Teoria Geral do Emprego, do Juro e da Moeda", publicada pela primeira vez em 1936, a referida taxa consiste na "recompensa pela renúncia à liquidez", ou seja, em uma compensação por não se fazer uso do dinheiro no presente. Essa renúncia faz sentido, sendo um comportamento racional, apenas se o custo de abdicar de um consumo presente for recompensado no futuro. Esse benefício é adquirido com o recebimento dos juros.

Conforme Weber (2006), no princípio, os juros eram um fenômeno de direito aplicável ao estrangeiro, uma vez que não ocorriam dentro da comunidade de tribo, de linhagem ou de povoado. Antes mesmo da existência da moeda cunhada (que ocorreu na Grécia), registros históricos mostram que no Neolítico (por volta de 5.000 a. C.) o crédito se tornou importante, estimulando a acumulação de capital e o crescimento das cidades. Jantalia (2012) informa que geralmente o empréstimo era de grãos e metais, que eram devolvidos com acréscimo da coisa emprestada, configurando, desta forma, os juros.

Outrossim, a determinação do patamar dos juros segue a lei da oferta e demanda, ou seja, é determinada via mercado, salvo nos casos em que há determinação legal expressa. Basicamente, em um mercado competitivo, a taxa de juros vigente encontra-se na interseção das curvas de oferta e demanda (procura) de fundos emprestáveis, conforme se verifica no gráfico que segue:

\section{Gráfico 1 - Oferta e Demanda de Fundos Emprestáveis}

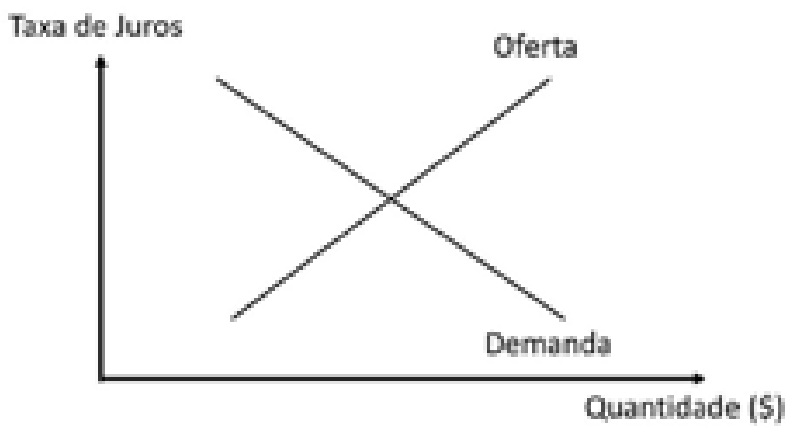

Fonte: Elaboração Própria

Por meio deste gráfico percebe-se que, em um livre mercado, a taxa de juros vigente é função da oferta de moeda e da demanda de fundos emprestáveis. Elevação da procura por fundos, por exemplo, quando ocorre uma elevação na renda das pessoas, eleva a taxa de juros. Igualmente, uma elevação no risco de ofertar crédito, por exemplo, em razão de uma recessão econômica, retrai a oferta, fato que eleva a taxa de juros. A razão de evidenciar esta teoria, é para esclarecer que os 
juros estão relacionados com o funcionamento do mercado em questão, que impacta na oferta e demanda, ou seja, depende do risco do negócio, das expectativas dos agentes, entre outras variáveis.

A aplicação de taxas de juros no Brasil, contudo, tem sido objeto de várias controvérsias, sendo uma delas sua aplicabilidade como índice de correção monetária, ${ }^{3}$ inclusive devido ao fato de que há diversos conceitos relacionados a juros, fato que dificulta para a população em geral seu entendimento. Os tópicos que seguem explicitam alguns conceitos e leis, embora seja imprescindível ressaltar que não esgotam os assuntos, os quais são por vezes objeto de leis específicas, bem como de Súmulas dos Tribunais Superiores. Assim, as leis aqui apresentadas têm como único objetivo esclarecer melhor o entendimento dos conceitos relacionados a juros.

\subsection{Dos juros remuneratórios}

Os juros remuneratórios, também chamados de compensatórios, visam remunerar o capital. Trata-se de espécie de compensação devida em razão da utilização do capital pertencente a terceiro (GONÇALVES, 2014). Segundo João de Matos Antunes Varela (1999, p. 870 apud PEREIRA, 2006, p. 36):

Os juros remuneratórios são os frutos civis, constituídos por coisas fungíveis que representam o rendimento de uma obrigação de capital, a compensação que o obrigado deve pela utilização temporária de certo capital, sendo o seu montante em regra previamente determinado como uma fração do capital correspondente ao tempo da sua utilização, variando o seu montante em função do valor do capital devido, do tempo durante o qual se mantém a privação deste por parte do credor, e da taxa de remuneração fixada por lei ou estipulada pelas partes.

Inicialmente disciplinados pela Lei de Usura (BRASIL, 1933), os juros no âmbito do Sistema Financeiro Nacional (SFN) passaram a ser disciplinados nos termos da Lei ${ }^{\circ} 4.595$ de 31 de dezembro de 1964 (BRASIL, 1964).

Nesse sentido, o art. $4^{\circ}$, inciso IX, da Lei $n^{\circ}$ 4595/1964 dispõe que compete ao Conselho Monetário Nacional, observadas as diretrizes estabelecidas pelo Presidente da República, "Limitar, sempre que necessário, as taxas de juros, descontos comissões e qualquer outra forma de remuneração de operações e serviços bancários ou financeiros, inclusive os prestados pelo Banco Central da República do Brasil [...]” (BRASIL, 1964).

A fim de dirimir dúvidas frequentemente suscitadas a respeito dos juros no Brasil, vale a pena descrever a Súmula n⿳ 596 do STF (BRASIL, [2006]), que prevê que "As disposições do Decreto $\mathrm{n}^{\circ} 22.626$ de 1933 não se aplicam às taxas e aos outros encargos cobrados nas operações realizadas por instituições públicas ou privadas, que integram o Sistema Financeiro Nacional”.

3 Outras controvérsias que têm sido objeto de revisão judicial são a verificação da existência de juros abusivos e/ou anatocismo. 
Embora a citada Súmula exclua do alcance do referido Decreto as instituições que integram o SFN, este ainda alcança as instituições não integrantes do SFN, como ocorre nos casos de financiamento direto com construtoras.

\subsection{Dos juros de mora}

Por sua vez, os juros de mora têm função penalizadora, sendo passível de aplicação quando do atraso da obrigação. Nas palavras de Gonçalves (2014, p. 382), os “Moratórios são os incidentes em caso de retardamento na sua restituição ou de descumprimento de obrigação", podendo ser convencionados ou não, correndo a partir da constituição em mora do devedor.

A incidência dos juros moratórios já se encontrava prevista no Decreto $\mathrm{n}^{\circ} 22.626$ de 1933 , que dispõe, em seu art. 5", que "Admite-se que pela mora dos juros contratados estes sejam elevados de 1\% e não mais" (BRASIL, 1933). Igualmente, perante o STJ, no âmbito da Súmula n. ${ }^{\circ}$ 379, publicada em 05/05/2009, restou consignado que "Nos contratos bancários não regidos por legislação específica, os juros moratórios poderão ser convencionados até o limite de $1 \%$ ao mês" (BRASIL, [2009]).

\subsection{Dos juros simples e compostos}

Quanto à forma de capitalização dos juros, estes podem ser simples ou compostos. Os juros simples capitalizam os juros uma única vez, ao final do período de cálculo. Os juros compostos capitalizam os juros ao principal periodicamente, ou seja, os juros são agregados ao capital inicial, por exemplo, mensalmente ou anualmente. De acordo com Gonçalves (2014, p. 277), "Os juros simples são sempre calculados sobre o capital inicial. Os compostos são capitalizados anualmente, calculando-se juros sobre juros, ou seja, os que forem computados passarão a integrar o capital”.

Este conceito gera frequentes questionamentos, uma vez que o Decreto ${ }^{\circ} 22.626$ de 1933 veda a capitalização de juros em periodicidade inferior a um ano. Nesse sentido, consta no art. $4^{\mathrm{o}}$ do referido decreto que "É proibido contar juros dos juros: esta proibição não compreende a acumulação de juros vencidos aos saldos líquidos em conta corrente de ano a ano" (BRASIL, 1933). Esta vedação foi ainda objeto de análise pelo STF, o qual publicou a seguinte Súmula ${ }^{\circ}$ 121: "É vedada a capitalização de juros, ainda que expressamente convencionada" (BRASIL, [1963]). Todavia, a Súmula n ${ }^{\circ} 539$ do STJ (2015), em decisão datada de 10/06/2015 esclarece que “É permitida a capitalização de juros com periodicidade inferior a anual em contratos celebrados com instituições integrantes do Sistema Financeiro Nacional a partir de 31/3/2000 (MP n. 1.96317/2000, reeditada como MP n. 2.170-36/2001), desde que expressamente pactuada" (BRASIL, [2015]).

Em suma, tem-se que a capitalização de juros é permitida, inclusive em periodicidade inferior a um ano (diferentemente do expresso no Decreto $\mathrm{n}^{\circ} 22.626$ de 1933), em contratos celebrados com instituições integrantes do SFN, a partir de 31/3/2000, mas com a ressalva de que somente se expressamente pactuada. 


\subsection{Dos juros nominais e efetivos}

A taxa de juro nominal, para Samanez (2010, p. 36), é "uma taxa referencial em que os juros são capitalizados (incorporados ao principal) mais de uma vez no período a que a taxa se refere." Desta forma, é uma “taxa declarada ou taxa cotada que não incorpora capitalizações”, não representando, desta forma, o verdadeiro custo do capital. Este é encontrado na taxa efetiva, cuja fórmula segue:

$$
1+\mathrm{i}_{\mathrm{e}}=\left(1+\mathrm{i}_{\mathrm{n}} / \mathrm{q}\right)^{\mathrm{q}}
$$

Onde:

- $\quad \mathrm{i}_{\mathrm{e}}=$ Taxa de juros efetiva

- $\quad$ in= Taxa de juros nominal

- $\quad \mathrm{q}=$ Quantidade de capitalizações

Exemplificando, na caderneta de poupança, os juros nominais são de 6\% ao ano capitalizados mensalmente. Substituindo-se os dados na fórmula (1) temos:

$$
1+\mathrm{i}_{\mathrm{e}}=(1+0,06 / 12)^{12}
$$

Multiplicando-se o resultado por 100 (para se ter a taxa em percentuais), encontra-se a taxa efetiva de juros de 6,17\% ao ano. Este conceito também gera dúvidas, pois nem sempre os contratos esclarecem se uma taxa é nominal ou efetiva.

\subsection{DOS JUROS NOMINAIS E REAIS}

A taxa real de juros é conceituada em Gimenes (2009) da seguinte forma: "É o que realmente o investimento proporcionou de retorno, descontada a inflação do período em questão". Sua fórmula de cálculo é apresentada a seguir.

$$
\left(1+i_{n}\right)=\left(1+i_{r}\right) \times\left(1+i_{j}\right)
$$

Onde:

- $\mathrm{i}_{\mathrm{r}}=$ taxa de juros real

- $\mathrm{i}_{\mathrm{n}}=$ taxa de juros nominal

- $\mathrm{i}_{\mathrm{j}}=$ taxa de inflação. 
Exemplificando, supondo uma aplicação financeira em que a taxa nominal de juros é de $10 \%$ ao ano, e uma taxa de inflação no período de 5\%, o ganho real desta aplicação é encontrado usandose a fórmula (2):

$$
(1+0,1)=\left(1+\mathrm{i}_{\mathrm{r}}\right) \times(1+0,05)
$$

Isolando a taxa real de juros $\left(\mathrm{i}_{\mathrm{r}}\right)$ chegamos na igualdade:

$$
\mathrm{i}_{\mathrm{r}}=1,0945-1=0,0476
$$

Em percentuais, a taxa nominal (também chamada de aparente) é de 5\%, e o ganho real da aplicação foi de $4,76 \%$.

Uma menção à taxa real estava presente na Constituição Federal de 1988 (BRASIL, 1988), art. $192, \S 3^{\circ}$, já revogado pela EC 40/2003:

As taxas de juros reais, nelas incluídas comissões e quaisquer outras remunerações direta ou indiretamente referidas à concessão de crédito, não poderão ser superiores a doze por cento ao ano; a cobrança acima deste limite será conceituada como crime de usura, punido, em todas as suas modalidades, nos termos que a lei determinar.

O tópico que segue tem como objetivo entender a distinção entre juros e correção monetária.

\section{DO CONCEITO DE ATUALIZAÇÃO MONETÁRIA}

Atualização/correção monetária é um expediente que tem como objetivo atualizar um valor expresso em moeda, no tempo. Milone (2006) a entende como "o reajuste de valores monetários a partir de algum índice que expresse a variação média de preços de dada época e local." Logo, atualização/correção monetária é um expediente que tem como objetivo atualizar um valor expresso em moeda, no tempo, não se confundindo, portanto, com os conceitos de juros.

Para Pinho e Vasconcellos (2004), a prolongada convivência com a inflação tem sido uma das características marcantes da economia brasileira e é associada à disseminação, desde meados da década de 1960, da chamada correção monetária. Para se fazer a atualização monetária, vários índices que medem inflação podem ser usados. A escolha do índice dependerá do objeto que terá o valor atualizado. Entre os índices brasileiros mais conhecidos estão o Índice de Preços ao Consumidor Ampliado (IPCA), o Índice Nacional de Preços ao Consumidor (INPC), ambos calculados pelo Instituto Brasileiro de Geografia e Estatística (IBGE); e o Índice Geral de Preços - Mercado (IGP - M), da Fundação Getúlio Vargas (FGV). Tendo em vista que o índice escolhido pelo STF para substituição da TR foi o IPCA-E, será feita uma breve explanação a respeito do mesmo.

Segundo o IBGE (2018), O IPCA-E foi criado em dezembro de 1991 e, a partir de janeiro 
de 1995, passou a ser divulgado trimestralmente. O IPCA-E é o acumulado trimestral do IPCA15. O período de coleta de dados abrange, em geral, do dia 16 do mês anterior ao 15 do mês de referência e na abrangência geográfica. A população-objetivo do IPCA-15 abrange as famílias com rendimentos de 1 a 40 salários mínimos, qualquer que seja a fonte, residentes em 11 áreas urbanas, as quais são: regiões metropolitanas de Belém, Fortaleza, Recife, Salvador, Belo Horizonte, Rio de Janeiro, São Paulo, Curitiba, Porto Alegre, além do Distrito Federal e do município de Goiânia.

Tabela 1- Ponderação do IPCA pelas Regiões Metropolitanas pesquisadas.

\begin{tabular}{|c|c|}
\hline Áreas Pesquisadas & Peso \\
\hline São Paulo & $30,67 \%$ \\
\hline Rio de Janeiro & $12,06 \%$ \\
\hline Belo Horizonte & $10,86 \%$ \\
\hline Porto Alegre & $8,40 \%$ \\
\hline Curitiba & $7,79 \%$ \\
\hline Salvador & $6,12 \%$ \\
\hline Recife & $4,20 \%$ \\
\hline Belém & $4,23 \%$ \\
\hline Goiânia & $3,59 \%$ \\
\hline Fortaleza & $2,91 \%$ \\
\hline Brasília & $2,80 \%$ \\
\hline São Luís & $1,87 \%$ \\
\hline Vitória & $1,78 \%$ \\
\hline Campo Grande & $1,51 \%$ \\
\hline Aracaju & $0,79 \%$ \\
\hline Rio Branco & $0,42 \%$ \\
\hline Fonte: Elaboração dos autores a partir de dados do IBGE (2020)
\end{tabular}

Fonte: Elaboração dos autores a partir de dados do IBGE (2020)

A Tabela 1 mostra que cada região possui importância distinta no cálculo. As diferenças de peso justificam-se segundo a população residente em cada região. Segundo o IBGE, Sudeste, Rio de Janeiro e Belo Horizonte possuem aproximadamente 39 milhões de habitantes, respondendo por quase $1 / 5$ da população brasileira, o que explica o maior peso dessas regiões no cálculo.

\section{DA SUBSTITUIÇÃO DA TR PELO IPCA-E, SOB A PERSPECTIVA DO STF}

Inicialmente, é preciso esclarecer que correção monetária das dívidas da Fazenda Pública encontra-se disciplinada no art.1-F, da Lei no 9.494, de 10 de setembro de 1997 (com redação dada pela Lei $\left.n^{\circ} 11.960 / 2009\right)$, que dispõe que:

Nas condenações impostas à Fazenda Pública, independentemente de sua natureza e para fins de atualização monetária, remuneração do capital e compensação 
da mora, haverá a incidência uma única vez, até o efetivo pagamento, dos índices oficiais de remuneração básica e juros aplicados à caderneta de poupança (BRASIL, 1997).

Salienta-se que, o índice oficial de remuneração básica aplicado à caderneta de poupança é a TR, uma taxa de juros.

Todavia, após julgamento do Recurso Extraordinário nº 870947, verifica-se que o STF afastou o uso da Taxa Referencial (TR) como índice de correção monetária dos débitos judiciais da Fazenda Pública, mesmo no período da dívida anterior à expedição do precatório.

O Recurso Extraordinário no 870947 foi interposto perante o STF pelo Instituto Nacional do Seguro Social (INSS) em meados de 2015, contra decisão da Quarta Turma do Tribunal Regional Federal da $5^{\text {a }}$ Região que assentou que não caberia a aplicação da Lei n. ${ }^{\circ}$ 11.960/2009 ao caso (referente ao benefício assistencial previsto no art. 203, V, da Constituição Federal) quanto aos juros e correção monetária (BRASIL, 2017).

Em 17 de abril de 2015 a repercussão geral da matéria foi reconhecida (Tema 810). Posteriormente, o STF firmou a seguinte tese de repercussão geral:

1) $O$ art. $1^{\circ}$-F da Lei $n^{\circ} 9.494 / 97$, com a redação dada pela Lei $n^{\circ} 11.960 / 09$, na parte em que disciplina os juros moratórios aplicáveis a condenações da Fazenda Pública, é inconstitucional ao incidir sobre débitos oriundos de relação jurídicotributária, aos quais devem ser aplicados os mesmos juros de mora pelos quais a Fazenda Pública remunera seu crédito tributário, em respeito ao princípio constitucional da isonomia (CRFB, art. $5^{\circ}$, caput); quanto às condenações oriundas de relação jurídica não-tributária, a fixação dos juros moratórios segundo o índice de remuneração da caderneta de poupança é constitucional, permanecendo hígido, nesta extensão, o disposto no art. $1^{\circ}$-F da Lei ${ }^{\circ}$ 9.494/97 com a redação dada pela Lei $n^{\circ} 11.960 / 09$; e 2) O art. $1^{\circ}$-F da Lei $n^{\circ}$ 9.494/97, com a redação dada pela Lei $\mathrm{n}^{\circ} 11.960 / 09$, na parte em que disciplina a atualização monetária das condenações impostas à Fazenda Pública segundo a remuneração oficial da caderneta de poupança, revela-se inconstitucional ao impor restrição desproporcional ao direito de propriedade (CRFB, art. $\left.5^{\circ}, \mathrm{XXII}\right)$, uma vez que não se qualifica como medida adequada a capturar a variação de preços da economia, sendo inidônea a promover os fins a que se destina (BRASIL, 2020).

Em suma, de acordo com a decisão proferida pelo STF, tem-se que: (i) quanto aos juros de mora, a inconstitucionalidade do art. $1^{\circ}$-F da Lei n. ${ }^{\circ} 11.960 / 1997$ é parcial, não se aplicando à condenação da Fazenda Pública em relações jurídico-tributárias; e (ii) quanto à atualização monetária, é inconstitucional a determinação de correção das condenações impostas à Fazenda Pública segundo a remuneração oficial da caderneta de poupança, por se tratar de restrição desproporcional ao direito de propriedade, já que tal índice é incapaz de capturar a variação de preços da economia.

Conforme consignado nos autos do RE 870947/2019, “[...] índices de correção monetária 
devem ser, ao menos em tese, aptos a refletir a variação de preços de caracteriza o fenômeno inflacionário, o que somente será possível se consubstanciarem autênticos índices de preços" (BRASIL, 2017). Ainda, tem-se que a correção monetária representa a mera recomposição do poder aquisitivo da moeda, em razão da inflação, não podendo ser predefinido. Por fim, indicouse o IPCA-E como índice de correção, a fim de manter o entendimento esboçado nas ADIs de $n^{\circ}$ 4.357 e $\mathrm{n}^{\circ} 4.425$.

Nota-se a preocupação com a preservação do poder de compra, no momento em que se reconhece que a taxa da caderneta de poupança não é o instrumento adequado para captar a variação de preços da economia, como objetiva-se demonstrar. Em seu lugar, o índice de correção monetária sugerido foi o Índice de Preços ao Consumidor Amplo Especial (IPCA-E), considerado mais adequado para recompor a perda de poder de compra, conforme demonstrou-se neste trabalho. Todavia, conforme foi demonstrado em Nishi (2015), como a variação da TR tem sido inferior à do IPCA, esta substituição impactará as contas do governo, em consequência da majoração de despesas: caso o governo seja deficitário, eleva-se o déficit; caso seja superavitário, reduz-se o superávit.

\section{CONCLUSÃO}

A atualização (ou correção) monetária é um instituto que visa preservar o valor da moeda, em razão da existência de inflação. Todavia, tem sido frequente o uso de taxas de juros para tal finalidade no Brasil, inclusive com previsão legal.

Em termos econômicos e metodológicos, a maneira correta de se efetuar atualização monetária é com uso de índices de preço, pois somente os índices de preço possuem metodologia de cálculo capaz de captar a variação dos preços. As taxas de juros, por visarem a remuneração do capital, relacionam-se com outros fatores, tais como o risco e prazo do investimento, e não guardam relação metodológica com a variação dos preços. Por este motivo, não são adequadas para serem usadas para fins de atualização monetária.

Desta forma, conclui-se que o uso de taxas de juros como instrumento de correção monetária é um equívoco que deve ser afastado da legislação, pois resulta no prejuízo a uma das partes, ao pagar mais (ou menos) do que deveria.

Em setembro de 2017, o STF manifestou-se a respeito deste assunto, mais precisamente no que tange aos débitos judiciais da Fazenda Pública. No julgamento do Recurso Extraordinário $\mathrm{n}^{\circ}$ 870947, decidiu pelo afastamento da TR, em favor do IPCA-E, como índice de atualização monetária.

Conclui-se que tal decisão, ao eliminar o uso de uma taxa de juros, no caso a TR, para fins de atualização monetária, corrigiu este equívoco na atualização dos débitos da Fazenda Pública.

\section{REFERÊNCIAS}

BRASIL. [Constituição (1988)]. Constituição da República Federativa do Brasil. Brasília, 
DF: Presidência da República, 1988. Disponível em: http://www.planalto.gov.br/ccivil_03/ constituicao/constituicao.htm. Acesso em: 15 jun. 2018.

BRASIL. Câmara dos Deputados. Projeto de Lei ${ }^{0}$ 4566/2008. Dispõe sobre a remuneração das contas vinculadas do Fundo de Garantia do Tempo de Serviço - FGTS; estabelece regime de transição para o aumento dessa remuneração; altera a Lei n ${ }^{\circ}$ 8.036, de 11 de maio de 1990; e dá outras providências. Brasília, DF: Câmara dos Deputados, 2008. Disponível em: https://www. camara.leg.br/proposicoesWeb/fichadetramitacao?idProposicao=422415. Acesso em: 26 fev. 2019.

BRASIL. Decreto $\mathbf{n}^{0} 22.626$ de 07 de abril de 1933. Dispõe sobre os Juros nos Contratos e dá outras providências. Brasília, DF: Presidência da República, 1933. Disponível em: http://www. planalto.gov.br/ccivil_03/decreto/d22626.htm. Acesso em: 15 jun. 2018.

BRASIL. Lei n 11.960 de 29 de junho de 2009. Altera e acresce dispositivos às Leis nos 9.639, de 25 de maio de 1998, e 11.196, de 21 de novembro de 2005, para dispor sobre parcelamento de débitos de responsabilidade dos Municípios [...] e dá outras providências Brasília, DF:

Presidência da República, 2009. Disponível em: http://www.planalto.gov.br/ccivil_03/_ato20072010/2009/lei/111960.htm. Acesso em: 15 jun. 2018.

BRASIL. Lei ${ }^{\circ} 4.595$ de 31 de dezembro de 1964. Dispõe sobre a Política e as Instituições Monetárias, Bancárias e Creditícias, Cria o Conselho Monetário Nacional e dá outras providências. Brasília, DF: Presidência da República, 1964. Disponível em: http://www.planalto. gov.br/ccivil_03/leis/14595.htm. Acesso em: 15 jun. 2018.

BRASIL. Lei no 8.036, de 11 de maio de 1990. Dispõe sobre o Fundo de Garantia do Tempo de Serviço, e dá outras providências. Brasília, DF: Presidência da República, 1990. Disponível em: http://www.planalto.gov.br/ccivil_03/leis/18036consol.htm. Acesso em: 8 out. 2015.

BRASIL. Lei ${ }^{0}$ 9.494, de 10 de setembro de 1997. Disciplina a aplicação da tutela antecipada contra a Fazenda Pública, altera a Lei n ${ }^{0} 7.347$, de 24 de julho de 1985, e dá outras providências. Brasília, DF: Presidência da República, 1997. Disponível em: http://www.planalto.gov.br/ ccivil_03/leis/19494.htm. Acesso em: 10 jan. 2020.

BRASIL. Superior Tribunal de Justiça. Recuso Especial no 1.614.874 SC. Recorrente: Sindicato dos Trabalhadores em água, esgoto e meio ambiente do Estado de Santa Catarina. Recorrido: Caixa Econômica Federal. Relator: Min. Benedito Gonçalves. Julgado em 22 fevereiro 2018. Disponível em: https://stj.jusbrasil.com.br/jurisprudencia/549906499/recurso-especial-resp1614874-sc-2016-0189302-7/decisao-monocratica-549906518. Acesso em: 10 jan. 2020.

BRASIL. Superior Tribunal de Justiça. Súmula 379. Nos contratos bancários não regidos por legislação específica, os juros moratórios poderão ser convencionados até o limite de $1 \%$ ao mês. Brasília, DF: Superior Tribunal de Justiça, [2009]. Disponível em: https://www.stj.jus.br/ publicacaoinstitucional/index.php/sumstj/article/download/5552/5675. Acesso em: 30 mar. 2015.

BRASIL. Superior Tribunal de Justiça. Súmula 539. É permitida a capitalização de juros com periodicidade inferior à anual em contratos celebrados com instituições integrantes do Sistema Financeiro Nacional a partir de 31/3/2000. Brasília, DF: Superior Tribunal de Justiça, [2015]. Disponível em: https://scon.stj.jus.br/SCON/sumanot/toc.jsp?livre=(sumula\%20adj1\%20 \%27539\%27).sub.\#TIT1TEMA0. Acesso em: 30 mar. 2018. 
BRASIL. Supremo Tribunal Federal. Ação Direta de Inconstitucionalidade $\mathbf{n}^{\circ} 5090$ (ADI 5090/DF). Disponível em: http://portal.stf.jus.br/processos/detalhe.asp?incidente $=4528066$. Acesso em: 26 fev. 2019.

BRASIL. Supremo Tribunal Federal. Recurso Extraordinário no 870.947. Sergipe. Reclamante: Instituto Nacional do Seguro Social - INSS. Reclamado: Derivaldo Santos Nascimento.

Relator: Min. Luiz Fux. Julgado em 20 setembro de 2017. Disponível em: http://redir.stf.jus.br/ paginadorpub/paginador.jsp?docTP=TP\&docID=14080728. Acesso em: 6 mar. 2019.

BRASIL. Supremo Tribunal Federal. Súmula 121. É vedada a capitalização de juros, ainda que expressamente convencionada. Brasília, DF: Supremo Tribunal Federal, [1963]. Disponível em: http://www.stf.jus.br/portal/jurisprudencia/menuSumarioSumulas.asp?sumula=2000. Acesso em: 15 jun. 2018.

BRASIL. Supremo Tribunal Federal. Súmula 596. As disposições do Decreto 22.626/1933 não se aplicam às taxas de juros e aos outros encargos cobrados nas operações realizadas por instituições públicas ou privadas, que integram o Sistema Financeiro Nacional. Brasília, DF: Supremo Tribunal Federal, [2006]. Disponível em: http://www.stf.jus.br/portal/jurisprudencia/ menuSumarioSumulas.asp?sumula=2017. Acesso em: 15 jun. 2018.

BRASIL. Supremo Tribunal Federal. Tese com Repercussão Geral n⿳0 810. Disponível em: http://www.stf.jus.br/portal/jurisprudenciaRepercussao/abrirTemasComRG.asp. Acesso em: 6 jan. 2020.

CARVALHO, Cristiano; JOBIM, Eduardo. O direito tributário e a intepretação econômica do direito: deveres instrumentais, custos de conformidade e custos de transação. In: TIMM, Luciano Benetti (org.). Direito e economia. Porto Alegre: Livraria do Advogado, 2008.

GIMENES, Cristiano Marchi. Matemática financeira com HP 12C e excel: uma abordagem descomplicada. 2. ed. São Paulo: Pearson Prentice Hall, 2009.

GONÇALVES, Carlos Roberto. Direito civil brasileiro: teoria geral das obrigações. 11. ed. São Paulo: Saraiva, 2014. v. 2.

GUERRA, Fernando. Matemática financeira através da HP12-C. 2. ed. Florianópolis: Editora da UFSC, 2001.

IBGE. Índice nacional de preços ao consumidor amplo especial - IPCA-E. Disponível em: https://www.ibge.gov.br/estatisticas-novoportal/economicas/precos-e-custos/9262-indicenacional-de-precos-ao-consumidor-amplo-especial.html? $=\& \mathrm{t}=$ o-que-e. Acesso em: 18 jun. 2018.

IBGE. Nota técnica 01/2018: abrangência geográfica. Disponível em: https://www.ibge.gov.br/ estatisticas/economicas/precos-e-custos/9262-indice-nacional-de-precos-ao-consumidor-amploespecial.html?=\&t=notas-tecnicas. Acesso em: 7 jan. 2020.

JANTALIA, Fabiano. Juros bancários. São Paulo: Atlas, 2012.

KEYNES, John Maynard. A teoria geral do emprego do juro e da moeda. São Paulo: Abril Cultural, 1996.

MILONE, Giuseppe. Matemática financeira. São Paulo: Thomson Learning, 2006. 
NELSON, Rocco Antonio Rangel Rosso; CORREIA, Marcos Vasconcelos. Fundo de garantia por tempo de serviço (FGTS) - em busca da correção "justa". Revista de La Facultad de Ciencias Econômicas - UNNE, Chaco, n. 14, 2015. Disponível em: https://memoria.ifrn.edu. $\mathrm{br} / \mathrm{bitstream} /$ handle/1044/767/revista_14_AyP_digital.pdf? sequence=1\&isAllowed=y\#page=75. Acesso em: 14 dez. 2017.

NISHI, Lisandro Fin. Análise econômica do projeto de lei que altera a remuneração do FGTS. Revista da Associação Mineira de Direito e Economia, Belo Horizonte, v. 13, 2015.

PEREIRA, Thiago Custódio. A limitação dos juros remuneratórios nos contratos bancários. 2006. 67 f. Trabalho de Conclusão de Curso (Graduação em Direito) - Universidade do Vale do Itajaí, Itajaí, 2006.

PINHO, Diva Benevides; VASCONCELLOS, Marco Antonio Sandoval (org.). Manual de economia. São Paulo: Saraiva, 2004.

SAMANEZ, Carlos Patrício. Matemática financeira. 5. ed. São Paulo: Pearson Prentice Hall, 2010.

WEBER, Max. História geral da economia. São Paulo: Centauro, 2006.

Como citar: BURG, Amanda Karolini; GONÇALVES, Everton das Neves; NISHI, Lisandro Fin. Atualização monetária dos débitos judiciais da fazenda pública sob a perspectiva do supremo tribunal federal. Scientia Iuris, Londrina, v. 25, n. 1, p. 163-177, mar. 2021. DOI: 10.5433/2178-8189.2021v25n1p163. ISSN: 2178-8189.

Recebido em 09/01/2020

Aprovado em 01/05/2020 